\title{
A questão do outro e o diálogo*
}

\author{
NADJA HERMANN \\ Pontifícia Universidade Católica do Rio \\ Grande do Sul, Porto Alegre, RS, Brasil
}

\section{RESUMO}

Este artigo situa a questão do outro no âmbito da ética em educação. Inicialmente apresenta esclarecimentos sobre o tema para, em seguida, expor a interpretação fenomenológica de Bernhard Waldenfels, que mostra os limites de nosso entendimento e defende a forma de acesso ao outro como uma "peculiar lógica de resposta", rompendo com a abordagem dialógica. $\mathrm{Na}$ sequência, apresenta a posição de Hans-Georg Gadamer, que retoma o diálogo platônico baseado na hermenêutica filosófica, retendo o lógos que pode ser compartilhado por todos, de modo que construa uma ponte entre o eu e o outro. Por fim, indica o potencial explicativo das duas posições para compreender a dimensão tensional presente na relação com a alteridade. Os esforços educacionais de ir ao encontro da singularidade do outro requer ultrapassar uma visão metafísica apropriadora. $\mathrm{Na}$ experiência dialógica alojam-se as expectativas de uma abertura ética para criarmos um mundo comum.

\section{PALAVRAS-CHAVE}

outro; fenomenologia do estranho; diálogo hermenêutico.

* Este trabalho faz parte da pesquisa “Ética e educação: a questão do outro II”, financiada pelo Conselho Nacional de Desenvolvimento Científico e Tecnológico (CNPq) por meio de bolsa de Produtividade em Pesquisa. 


\section{THE ISSUE OF THE OTHER AND DIALOGUE}

\section{ABSTRACT}

The article places the issue of the other in the sphere of ethics in education. It initially explains the topic and then presents the phenomenological interpretation of Bernhard Waldenfels, who shows the limits of our understanding and advocates the form of access to the other as a "peculiar logic of response", breaking with the dialogical approach. Next, it presents the position of Hans-Georg Gadamer, who takes up again the platonic dialogue beginning with philosophical hermeneutics, retaining the logos which can be shared by all, so as to build a bridge between the self and the other. Finally, it indicates the explanatory potential of the two positions to understand the tensional dimension present in the relationship with alterity. The educational efforts of taking in the uniqueness of the other require going beyond an appropriating metaphysical vision. The expectations of an ethical opening to create a common world are lodged in the dialogical experience.

\section{KEYWORDS}

other; phenomenology of the alien; hermeneutical dialogue.

\section{LA CUESTIÓN DEL OTRO Y EL DIÁLOGO}

\section{RESUMEN}

El artículo sitúa la cuestión del otro en la esfera de la ética en la educación. Inicialmente se explica el tema y, a continuación, se presenta la interpretación fenomenológica de Bernhard Waldenfels, que muestra los límites de nuestra comprensión y defiende la forma de acceso al otro como una "lógica peculiar de respuesta”, rompiendo con el enfoque dialógico. A continuación se presenta la posición de Hans-Georg Gadamer, que retoma el principio dialógico platónico desde la perspectiva de la hermenéutica filosófica, en que el lógos puede ser compartido por todos, con el fin de construir un puente entre el yo y el otro. Por último, indica el potencial explicativo de las dos posiciones para entender la dimensión de la tensión presente en la relación con la alteridad. Los esfuerzos educativos de ir al encuentro de la singularidad del otro van más allá de una visión metafísica de apropiación. Las experiencias dialógicas alojan las expectativas de una abertura ética para crear un mundo común.

\section{PALABRAS CLAVE}

otro; fenomenología de lo extraño; diálogo hermenéutico. 


\title{
$A$ verdade essencial é o desconhecido que me habita e a cada amanhecer me dá um soco.
}

\begin{abstract}
Por ele sou também observado com ironia, desprezo, incompreensão. $E$ assim vivemos, se ao confronto se chama viver, unidos, impossibilitados de desligamento, acomodados, adversos, roídos de infernal curiosidade.
\end{abstract}

Carlos Drummond de Andrade, 2001, p. 1.237

Considerando o caráter interativo do processo pedagógico, a compreensão da relação entre o eu e o outro, entre o próprio e o estranho, amplia a discussão ética, com largas consequências para a educação em sociedades pluralistas. Como não podemos supor nenhuma certeza social nem antropológica de determinada forma de moral para daí em diante ordenar o mundo da vida e suas condições de aplicação, os esforços a respeito das questões éticas em educação devem se direcionar a uma "heurística moral do pensamento e da ação pedagógica" (Zirfas, 1999, p. 33), ${ }^{1}$ o que inclui múltiplas tarefas, desde a justificação das normas até o esclarecimento das motivações da ação moral e de seus paradoxos. Nessa perspectiva, assume relevância a pergunta pelo outro e se é possível a educação fazer justiça à sua singularidade, o que invoca também a pergunta pela possibilidade de o diálogo constituir-se em um modo de acesso ao outro. Esse tema interpela o processo formativo, trazendo o confronto com os limites de pressupostos teóricos que apresentam dificuldades históricas no reconhecimento daquilo que escapa aos padrões idealizados.

A herança metafísica ocidental compreende a questão do outro baseada na identidade do ser, criando amarras que dificultam uma dialética entre a identidade de si e o outro, em que o mesmo e o próprio possam estar impregnados pelo outro e pelo estranho. Profundamente influenciada pelos dualismos presentes nessa herança, tais como corpo e alma, civilização e barbárie, razão e desrazão, a educação tende a ver o outro como tudo o que se opõe às idealizações: o bárbaro, o selvagem, o infiel. Transpõe, tanto para o cotidiano como para o âmbito das especialidades científicas e também para o âmbito cultural, o peso interpretativo dessas oposições e identifica o educando como o desviado, o desadaptado, o desobediente, o hiperativo etc. Por trás dessas classificações existem os vestígios de uma herança que possui íntima relação com a ética e suas bases fundadoras, sobretudo na dificuldade em reconhecer algo de estranho no cosmos, na razão, na cultura ou em nós mesmos. Contudo, nem sempre nossa experiência ética é orientada pela pretendida clareza do entendimento e da autodeterminação individual, pois é o outro que nos atrai,

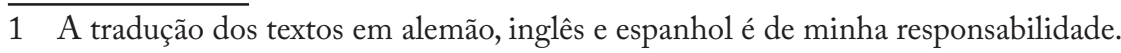


nos perturba e nos convoca a acolhê-lo. Tornamo-nos quem somos pela resposta a essa convocação e somos, muitas vezes, surpreendidos pelo outro que nos habita.

$\mathrm{Na}$ tentativa de contextualizar o problema para a ética em educação, este artigo inicialmente apresenta esclarecimentos e dificuldades conceituais a respeito do outro para em seguida expor a interpretação fenomenológica na perspectiva de Bernhard Waldenfels (2007), que mostra os limites de nosso ver, sentir e falar, e defende a forma de acesso ao outro como uma "peculiar lógica de resposta", rompendo com a abordagem dialógica. $\mathrm{Na}$ sequência, o texto expõe a posição de Hans-Georg Gadamer (1990,1993), que retoma o diálogo platônico com base na hermenêutica filosófica, retendo o lógos que pode ser compartilhado por todos, de modo que construa uma ponte entre o eu e o outro. Por fim, o artigo indica o potencial explicativo das duas posições para compreender a dimensão tensional presente em toda a relação com a alteridade. Os esforços educacionais de ir ao encontro da singularidade do outro exigem ultrapassar uma visão metafísica apropriadora e compreender os limites da consciência intencional. Como possuidores de linguagem, somos seres sempre suscetíveis a novas compreensões do outro e de nós mesmos. E nessa experiência alojam-se as expectativas de uma abertura ética que mantenha a relação com a alteridade, supere o universalismo que assimila e nivela, para criarmos um mundo comum.

\section{ETIMOLOGIA, ESCLARECIMENTOS CONCEITUAIS E OUTRAS APROXIMAÇÕES}

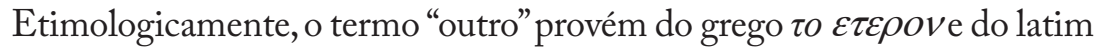
alteritas. Costuma ser empregado como equivalente à alteridade, que significa constituir-se como outro. No discurso filosófico, de um modo geral, o outro é uma categoria utilizada no trabalho de identificação e diferenciação, do qual surge o par conceitual identidade (ipseidade) e alteridade (diversidade), par este que se contrapõe, pois o outro é posto como limite da identidade. Trata-se de distinguir, por um processo de delimitação, o mesmo ( $\tau \alpha v \tau o v$, idem) que se opõe ao outro ( $\varepsilon \tau \varepsilon \rho o v$, alius). Por esse processo distinguimos, por exemplo, uma maçã de um pêssego.

O pensamento grego estabelece a identidade e a diferença como a relação fundamental tanto no plano lógico como no ontológico, e isso teve profunda influência na constituição de nossa compreensão sobre o que seria o homem e suas relações com o outro. O uno é o princípio identitário e a origem de todo o ser; já a diferença se estabelece em relação à identidade. Esse modo de filosofar cria as condições para pensar o outro como contraposição à identidade, num contexto metafísico relacionado com a fixidez.

Para situar de modo mais preciso a complexidade do problema, convém destacar as dificuldades linguísticas e conceituais a respeito do outro, as quais Waldenfels (2007, p. 4) nomeia como "sombras linguísticas e conceituais". Embora o tema se estabeleça em relação à identidade, gerando o duplo identidade (ipseidade) 
e alteridade (diversidade), o outro também aparece como o estranho, aquilo que é heterogêneo em relação a nós, associado ao inquietante, ao não familiar. O estranho não aparece pelo simples processo de delimitação, mas emerge de um processo simultâneo de inclusão e exclusão (idem, p. 7). Por esse mesmo processo, separamos as culturas, as diferenças de gêneros, o homem do animal, o Ocidente do Oriente etc., o que gera parte das dificuldades em reconhecer aquilo que não se ajusta aos nossos esquemas assimiladores.

Conforme observa Waldenfels (1997, p. 16), no século V a.C., essa dificuldade aparece com os gregos, que estabelecem uma diferença de natureza vertical entre eles e os bárbaros, designando-os inicialmente como aqueles que articulam mal as palavras, que balbuciam mal, sem estética. Posteriormente, esse significado se estende para aqueles povos que não possuem a cultura grega, passando a ser constituídos como o estrangeiro, o selvagem, o estranho, o outro. Muitos séculos mais tarde, Adorno (1998, p. 97) identifica barbárie com o "mal-estar destruidor da civilização", o que estaria vinculado às origens de nossa civilização, que se impôs com uma condição também de barbárie, pela existência de um "impulso destruidor". Há uma espécie de rudeza e brutalidade imanente à cultura que promove atos de violência. Aquilo que é estranho, que escapa à uniformização, deve ser destruído.

No pensamento moderno, com base no princípio da subjetividade, o outro é tematizado como aquilo que tende à exclusão. $\mathrm{O}$ emprego da palavra aparece associado ao estranho da identidade, a tudo que lhe é contrário, distinto e inverso. Como lembra Ricoeur (1996), a filosofia do sujeito é paradigmática, pois na medida em que o "eu penso" cartesiano funda todas as relações, o eu se expressa sem a confrontação de algo fora de si mesmo, e isso configura uma espécie de prólogo a tal tema. Nas Meditaçôes, Descartes (1973b) mostra que a objetivação do pensamento, que pode garantir a verdade, não depende de outrem. A certeza está ligada apenas ao cogito, só há pensamento puro, e isso permite representar o mundo e dominar a natureza. A radical separação entre o pensar e a corporeidade, por exemplo, trouxe como consequência nossa dificuldade em lidar com a natureza, em reconhecer o outro em nós mesmos. Não só na dimensão intelectiva, mas também na dimensão moral o outro não é objeto de consideração. Em As paixões da alma, ao analisar paixões como a estima e a generosidade, Descartes (1973a) as remete, numa primeira instância, a si mesmo, e não ao outro. Assim, o sujeito moderno constitui-se sem apelo a nenhuma exterioridade, e, em tudo o que olharmos ao redor, veremos só o que lá pusemos, ou seja, nós mesmos.

A modernidade acentua uma relação hostil entre razão e sujeito, uma vez que a razão mantém o que é comum, e a subjetividade, por sua vez, tem de se manter para si mesma como individual. Quando o estranho entra em cena, ele interfere na ordem da razão e descentra o sujeito, desequilibra-o, a ponto de produzir o efeito de o "homem não se sentir completamente em casa" (Waldenfels, 2007, 
p. 4). ${ }^{2} \mathrm{O}$ sujeito, centro da relação com o mundo, percebe o limite de sua suposta soberania. E, mesmo que o pensamento ocidental, por meio da filosofia hegeliano-marxista, tenha elaborado o conceito de estranhamento ou alienação (Entfremdung), não se trata do mesmo que estranheza (Fremdheit). São conceitos diferentes e, prossegue Waldenfels (idem, ibidem), "só no século XX, a questão do outro se torna uma questão filosófica central, esboçada por Simmel, Benjamin, Adorno e Bloch, sistematicamente elaborada por Husserl, e, finalmente, radicalizada pelos fenomenologistas franceses".

Desse modo, a distinção entre o eu e o outro, entre o próprio e o estranho, não se reduz a uma oposição entre termos, mas implica uma fenomenologia e uma hermenêutica compreensiva, que configuram a experiência do outro como algo que acontece, capazes de reconhecer o aparecimento do estranho dentro do próprio eu em virtude do caráter intrassubjetivo e intracultural do outro. $\mathrm{O}$ outro já está interiorizado no eu, é uma espécie de duplo de mim mesmo. Nesse sentido, Waldenfels (2007, p. 12) destaca que nem a outreidade de mim mesmo nem o outro vêm em primeiro lugar, pois "se eu me torno a mim mesmo sendo tocado pelo outro e respondendo ao seu apelo, as duas dimensões se cruzam: eu estou fora de mim mesmo precisamente por ser duplicado pelo outro; e eu sou duplicado precisamente ficando fora de mim mesmo".

Cabe ainda registrar que a experiência do outro está vinculada à história de sua apropriação, e uma das formas mais expressivas dessa apropriação na tradição ocidental se refere ao egocentrismo, que reduz o estranho ao próprio, àquilo que é comum. O que não se articula pela razão tende a ser desvalorizado e até excluído. Trata-se de um individualismo exacerbado, possessivo, uma atomização do mundo, em que a luta de cada um pela autopreservação determina aquilo que se interpõe a tal processo como barreira e como estranho. A mesma situação se percebe no etnocentrismo, centrado na ideia de grupo, nação, tribo ou cultura e suas consequências na eliminação daquilo que não se enquadra nos modelos de razão e de vida considerados legítimos. Nessa perspectiva, a história da colonização é uma história da apropriação do mundo, que hoje passa por processos de descentramento, pois sabemos que não estamos em condições de identificar exatamente quem somos, já que muitas vozes nos cercam, e das quais não podemos nos apropriar. Em relação a esse aspecto, a obra de Tzvetan Todorov (2003), A conquista da América ,é exemplar. O autor relata a descoberta e a conquista da América pelos espanhóis, no século XVI, para mostrar o outro exterior a nós mesmos. Esse encontro, que em muitas circunstâncias gerou violência, é considerado o encontro "mais surpreendente da história", pois

ao mesmo tempo que obliterava a estranheza do outro exterior, a civilização ocidental encontrava um outro interior. Da era clássica até o fim do Romantismo (isto é, até hoje) os escritores e moralistas não param de descobrir que a

2 Trata-se de uma referência de Waldenfels à célebre afirmação de Freud: "o ego não é o senhor de sua própria casa" (1969, p. 178, grifo do original). 
pessoa não é uma, ou que ela não é nada, que eu é um outro, ou uma simples câmara de eco. Já não se acredita em homens-fera na floresta, mas descobriu-se a fera dentro do homem [...]. A instauração do inconsciente pode ser considerada como o ponto culminante dessa descoberta do outro em si mesmo. (idem, p. 362-363)

Todorov expõe, numa perspectiva antropológica, a duplicidade existente entre $\mathrm{o}$ interior e o exterior, indicando a fragilidade de uma abordagem lógica e epistemológica que insiste em não reconhecer o aparecimento do estranho dentro do próprio eu, para destacar o caráter intrassubjetivo e intracultural do outro. A dificuldade do eu com o outro acompanha a história ocidental e provoca confusões conceituais, como os supostos desníveis culturais no interior das assim chamadas sociedades civilizadas. A oposição entre cultura erudita e popular projeta uma hierarquia que foi posteriormente posta em questionamento pelos estudos da antropologia cultural e pela história das tradições. Nesse sentido, foram necessários vários séculos de dolorosas experiências para se compreender as profundas implicações éticas de certos modos de estruturar nosso acesso ao mundo que resultaram em perversos reducionismos interpretativos.

\section{A QUESTÃO DO OUTRO NA FENOMENOLOGIA DE WALDENFELS}

A fenomenologia, um método adequado para indagar as questões humanas, oferece uma abordagem em que o outro aparece no plano da experiência, ou seja, trata-se de como o outro nos é dado pela experiência, numa relação existencial. Com isso, evitam-se os equívocos de considerá-lo tomando-se por base um processo de identificação, ou de um modelo objetivo que configure sua verdade. Aqui se percorrem as veredas da suspeita aberta por Nietzsche e Freud quanto à autossuficiência da razão.

A pesquisa fenomenológica pensa a alteridade - o que inclui o outro, a diferença, o estranho -, trazendo uma contribuição nova em relação à tradição do pensamento, na qual o outro deixa de ser interpretado pelo si mesmo. Deve-se recordar que há diversas correntes fenomenológicas, mas Edmund Husserl (1859-1938) definiu precisamente o termo com sua profunda investigação. Se fenômeno não significa meramente a aparência, mas é tudo aquilo que se oferece à pura observação, a fenomenologia faz uma leitura do fenômeno, tal como se apresenta. Permite radicalizar a experiência, pois a entende, em primeiro lugar, como um acontecer no qual a coisa mesma aflora, com a qual somos confrontados. A "experiência faz, ou seja, sofremos algo e não produzimos algo"(Waldenfels, 1997, p. 19). Esse conceito, além de refutar a tradição do empirismo, interpõe-se também contra o racionalismo, que compreende a experiência baseada em categorias prévias de pensamento que a estruturam. Para a fenomenologia, ao contrário, a experiência significa um processo, no qual se forma e se articula sentido e, nesse processo, recebem-se e se estruturam 
os dados. Não há, portanto, a pressuposição de que a realidade e o modo de acesso à realidade sejam separados. A experiência supõe um estranhamento e uma alteridade.

O tema da experiência do outro é introduzido fenomenologicamente por Husserl (1992), na obra Meditaçôes cartesianas (Cartesianische meditationen, publicada em 1931). A subjetividade é constituída numa pluralidade de subjetividades - os outros me são dados não como meras coisas, mas numa coparticipação do ego. Especificamente na quinta meditação, Husserl aborda o outro no âmbito da experiência transcendental, em que o outro se dá para mim. Sua argumentação mantém ainda os influxos cartesianos, porque se encontra energicamente apoiada no eu. Nesse sentido, Husserl (1992, p. 118) afirma: "Do ponto de vista fenomenológico, o outro é uma modificação do 'meu' eu (que, por sua vez, adquire essa característica de ser 'meu' eu graças ao acoplamento necessário que os opõe)".

De que forma esse outro se apresenta? Ele aparece como um alter ego por analogia comigo mesmo, que sou um ego. Ao dar-se ele mesmo, ele se descobre tendo a mim como estranho. Isso, segundo Husserl (idem, p. 109, grifos do original), permite constituir o "domínio novo e infinito do estranho, de uma natureza objetiva e de um mundo objetivo em geral, ao qual pertencem os outros e eu próprio". E, ao dar-se, ele apresenta seu corpo, seus gestos, mas a força psicológica de suas vivências me escapam. É na presença do corpo que a consciência do alter ego aparece no eu. A citação seguinte explicita o outro na condição de sujeito:

Se me introduzo em outrem pelo pensamento e se penetro profundamente nos horizontes daquilo que lhe pertence, vou me debater de imediato com o seguinte fato: da mesma forma que o seu corpo se encontra no meu campo de percepção, o meu encontra-se no campo de percepção dele e, geralmente, ele se apreende tão imediatamente como "outro" para si como eu o apreendo como "outro" para mim. Vejo igualmente que a multiplicidade dos "outros" se apreende reciprocamente como "outros"; em seguida, posso apreender cada um dos "outros" não só como "outro", mas como se referindo a todos os que são "outros" para si e, portanto, ao mesmo tempo, imediatamente para mim próprio. (idem, p. 133)

A alteridade aparece na medida em que o outro é o mesmo que eu, mas impenetrável para mim. Trata-se de uma apreensão que não é simples. A experiência do outro passa a ser considerada como "a acessibilidade verificável do que é originalmente inacessível” (idem, p. 117). Essa definição husserliana assume posição de destaque na interpretação de Bernhard Waldenfels (1997, p. 26). Segundo Waldenfels, trata-se de um conceito determinado paradoxalmente, pois não se inicia com a definição do que é estranho, mas na forma de acessibilidade, que, por sua vez, é uma inacessibilidade. O estranho não é acessível a mim como ocorre com o próprio, que é acessível e pertencente a mim. Isso leva a reconhecer que o lugar do outro e do estranho na experiência é um não lugar. Ou seja, o estranho não se encontra à espera de ser conhecido, como um "ainda não". Ele se constitui como ausência, como distância e impossibilidade. 
Radicalizando a análise, Waldenfels entende a experiência do outro como resposta que não começa com nossa intenção, tampouco provém de um comum entendimento, mas de algo que acontece, que provoca uma resposta. Segundo o filósofo, o caminho que levou a pensar o outro como um si mesmo foi "pavimentado com muitas deficiências" (Waldenfels, 1998, p. 89). Um desses caminhos se refere ao universal formal, que sonega a pluralidade, criando dificuldade em reconhecer o que não é idêntico. Um segundo caminho conduz ao individualismo, à particularidade do eu, em que o outro é um espelhamento do si próprio.

Os dois casos podem ser exemplificados com situações educacionais cotidianas. O universal formal, presente nas idealidades pedagógicas, define padrões de comportamentos, características e normas de ação para alunos que deixam escapar aquilo que não se enquadra nessa determinação. Frequentemente sofre preconceitos quem não aprende no mesmo ritmo, não demonstra certas habilidades específicas, como a habilidade lógico-matemática, ou apresenta dificuldades na linguagem oral, porque o ideal, definido abstratamente, exige do aluno as características desde já pressupostas não só pelo professor, como também pela organização curricular e didático-pedagógica. Esse é o caso do universal (ideal) que exclui a diferença (o caso particular que se afasta do padrão idealizado). $\mathrm{O}$ individualismo exacerbado, por sua vez, cria dificuldades de interação, pois o que extrapola o restrito âmbito do eu obstaculiza o reconhecimento do outro; mais que isso, não permite abertura à experiência. Muitas ações violentas são geradas por esse processo de apropriação/ expropriação, vinculadas ao não reconhecimento daquilo que é diferente do eu. Em nenhum dos casos o outro é apreendido, pois ele não pode ser captado como transformação do próprio nem como um mero momento do universal.

Ao indicar os problemas de pensar o outro como um si mesmo, a abordagem de Waldenfels já se afasta da trilha de Husserl. Para dar conta do problema, Waldenfels desenvolve uma análise do outro como estranho. Quando abordado como uma estranheza relativa a nós, e não como "a coisa mesma", o estranho aparece como um déficit, pois

tudo o que é verdadeiro e bom para nós (pros hemas) se mede pelo que é verdadeiro e bom por si (haplós). O verdadeiro e bom em si irradia uma luz própria; na sombra de uma, por assim dizer, estranheza absoluta, em que aparecem unicamente os poderes do caos, do sem razão, do mal, da pura privatio veri et boni. Esse "mundo invertido" não fragmenta de modo algum o mundo verdadeiro, mas desperta um peculiar horror alieni. (Waldenfels, 1998, p. 89, grifos do original)

Diante dessa estranheza a nós relativa, Waldenfels propõe a experiência do outro como estranheza radical, que "sacode as raízes", que não entende mais o outro como déficit ou algo a superar. A primeira dimensão da estranheza se refere à fronteira que delimita o outro e faz surgir o estranho, porque ele não está localizado na ordem, aquilo que permite a tudo ter seu lugar. O filósofo refere diferentes ordens criadas pelo pensamento ocidental, como a ordem do cosmos grego, a ordem da 
criação e também a ordem racional universal, as quais estabelecem hierarquias e determinam o lugar. Diferenciamos algo sempre em relação a um ponto de referência, gerando um binômio (inclusão/exclusão, dentro/fora), e essa assimetria torna-se impossível de eliminar. O estranho, afirma Waldenfels (2007, p. 7),

emerge de um processo que realiza simultaneamente a inclusão (Eingrenzung) e a exclusão (Ausgrenzung). [...] A esfera do estranho é separada da esfera do próprio por um limiar, como é o caso de sono e insônia, saúde e doença, velhice e juventude, e ninguém jamais se encontra em ambos os lados do limiar ao mesmo tempo.

Outra dimensão do estranho se refere ao estranho em nós mesmos, pois ele já se encontra em mim. A experiência do estranho não se refere a algo que existe e que é inacessível, um objeto para o outro, mas que se apresenta num "duplo acontecer", em que "eu mesmo sou participante como o outro; porém, essa participação não acontece pari passu, mas no modo que eu próprio começo, não por mim mesmo, mas com a reivindicação do outro"(Waldenfels, 1997, p. 30). Ou seja, o duplo acontecimento do estranho pressupõe que há uma pretensão do outro e uma resposta ao outro.

O estranho se caracteriza, ainda, pela ambiguidade, pois é, ao mesmo tempo, tentador e ameaçador. É tentador porque abre novas possibilidades que não foram incluídas na ordem vigente, e ameaçador porque desestabiliza essa mesma ordem. Nesse sentido, vale destacar que a experiência estética, pelo que provoca de estranhamento, igualmente nos desestabiliza, constituindo-se num modo de aproximação do outro pela abertura que se instaura, mas isso não será objeto de discussão neste artigo.

Retomando a perspectiva aberta por Husserl da "acessibilidade que é originalmente inacessível”, Waldenfels (2007) questiona como é possível fazer a experiência do outro sem diminuir ou sem abolir sua estranheza. Como ter acesso ao outro sem degradá-lo ou eliminá-lo? Isso implica o reconhecimento de que a abertura do horizonte da experiência e do entendimento não é ainda suficiente para interromper o processo de apropriação (idem, p. 16). Ou seja, há uma ambiguidade nesse processo que mantém a ambos, o próprio e o outro.

Mas, se não convergimos em relação ao outro, como podemos construir um mundo comum e reconhecer normas com validade universal? Como podemos fazer justiça à singularidade do outro? Não deveria haver uma maneira de entendimento possível entre o eu e o outro? Há uma atitude ética que possibilite o acesso ao outro? Essas são questões centrais para a formação, justamente porque sua imanente exigência ética projeta a questão da relação com o outro, a orientação da ação correta válida para todos (universalidade da norma) e a capacidade de julgar e decidir considerando também os outros.

Uma das respostas a esses questionamentos tem sido o diálogo, que assume perspectivas diferenciadas dependendo da abordagem teórica. Waldenfels não subscreve a tradição clássica do diálogo, justamente porque ela pressupõe um equilibrio entre as partes e aponta para um consenso. Aspecto este que o filósofo não 
considera possível de acontecer diante das questões apontadas pela fenomenologia do estranho. Sua crítica dirige-se, sobretudo, ao caráter imponente assumido pelo diálogo que tudo quer abarcar, para o qual todos têm o mesmo acesso e no qual, do mesmo modo, pelo menos em longo prazo, tudo pode ser tratado. Isso pertence, segundo Waldenfels (1997, p. 33), “às ilusões de um pensamento totalizante”. Desse modo, ele se afasta da tentativa de encontrar nesse tipo de diálogo uma condição para corrigir o egocentrismo e o etnocentrismo e equilibrar o próprio e o estranho, ${ }^{3}$ o eu e o outro.

Sua posição parte do duplo acontecer referido anteriormente, ou seja, a pretensão do outro e a resposta ao outro, que exigem outra lógica de acesso, que não a proposta do diálogo nos moldes da tradição ocidental. Se consenso aqui não é possível, porque a pretensão do outro não se enquadra no campo comum de sentido, Waldenfels considera que há, contudo, correspondência, ou seja, é possível abrir-se à desorientação provocada pelo outro, fora do círculo da intencionalidade, que toma o outro num determinado sentido e não deixa espaço para que o estranho aconteça. A resposta ao outro não se dá no enquadramento das normas; ao contrário, ela rompe com a familiaridade da formação de sentido e das normas. O duplo acontecer do outro requer uma lógica de resposta inteiramente peculiar, na qual o filósofo inclui aspectos como a singularidade, a inevitabilidade e a assimetria.

$\mathrm{O}$ acontecer do outro traz a singularidade, que "evita a distinção entre particular e universal" (Waldenfels, 2007, p. 29). Não se trata de um caso individual entre muitos outros, em que o estranho seria incluído num sistema de regra que mais tarde se tornaria familiar. Ao contrário, trata-se de uma ruptura de sentido, uma ruptura no pensar tradicional que provoca novas formas de pensar e agir, nova ordem simbólica e novas obrigações, como pode ser observado em momentos como a Revolução Francesa, a violência de Auschwitz ou as experiências inovadoras artísticas ou científicas.

O estranho nos traz também a inevitabilidade e, portanto, não se enquadra na distinção entre fatos e normas. É uma necessidade que não se deduz de leis gerais, mas nos põe na situação de não poder não responder ao outro, uma vez tocados por ele. Mesmo não respondendo, já estamos diante de um tipo de resposta, o que evidencia a inevitabilidade de seu próprio acontecimento. Por fim, o estranho situa-se no âmbito da assimetria, que "rompe o equilíbrio do diálogo tradicional, que é orientado por objetivos comuns e segue regras comuns" (idem, p. 31). A pretensão do outro não se encontra num campo de sentidos compartilhados, nunca se esgota em sua compreensão. As ideias de universalidade, segundo Waldenfels, equalizam o outro, portanto, não teria sentido estabelecer uma simetria entre o próprio e o estranho.

3 Em entrevista concedida (Gehring; Fische, 2000, s/p.), o filósofo reafirma sua posição em favor de uma dialética aberta para com o outro, e não mais a posição anteriormente defendida por ele na obra Zwischenreich des Dialog (1971). 
O acesso ao outro, para esse filósofo, não se articula na tradição dialógica, mas na resposta provocada pelo acontecer do outro, que rompe com as respostas já disponíveis, embebidas em costumes e regras morais. A aproximação do estranho se efetiva como algo para o qual respondemos e, inevitavelmente, temos que responder como convite ou como desafio. Ele projeta novas questões morais e novas exigências.

\section{A QUESTÃO DO OUTRO NA HERMENÊUTICA DE GADAMER}

Neste ponto da argumentação, cabe a confrontação com o que está em jogo na formação ética - a relação com o outro - de modo que abra uma perspectiva de "lançar pontes e transpor distâncias", ${ }^{4}$ que retoma o movimento de abertura à alteridade sem se restringir à inacessibilidade e tampouco opera com a apropriação. Nesse sentido, introduzo a posição defendida por Hans-Georg Gadamer a respeito do diálogo, em que o modo de relação com o outro supõe uma intersubjetividade possível. Seu pensamento, então, se afastaria de uma posição apropriadora do outro, como o faz a herança metafísica? Essa é a questão delicada enfrentada por aqueles que educam, tanto pela relevância do reconhecimento do outro, como pela permanente reivindicação de a educação constituir-se pela interatividade. Se há outro, como acessá-lo? A intersubjetividade é possível? No que segue, exporei a proposta de Gadamer quanto à possibilidade de acesso ao outro pela dinâmica existencial, pois o ser humano é constitutivamente compreensivo e somos sempre suscetíveis a novas interpretações.

A hermenêutica filosófica de Gadamer concebe o outro por uma perspectiva diferente da filosofia da identidade e recupera a tradição dialógica socrática sem estreitá-la nos moldes da subjetividade moderna. O filósofo já havia sido suficientemente alertado dos embustes e enganos da consciência por Nietzsche e reteve de Heidegger a intuição fenomenológica do Dasein (ser aí), do ser do ente que se desvela e se autointerpreta. Portanto, ela não parte mais da consciência presa à metafísica, que tende sempre à assimilação do outro. Gadamer (1987, p. 87) faz um giro em direção à hermenêutica moderna, a "práxis da arte de compreender e fazer falar o estranho", centrada no "diálogo, porque nele a linguagem se forma, amplia e atua” (Gadamer, 1993, p. 436). A linguagem é uma forma de vida que permite uma abertura ao outro.

$\mathrm{Na}$ detalhada investigação desenvolvida sobre o sentido do diálogo filosófico, Hösle (2006, p. 28) destaca que só podemos entender o outro porque temos a capacidade de nos colocar no seu lugar, ter a percepção de suas expectativas: "A real intersubjetividade só funciona porque o sujeito duplica-se como mesmo, pode ver-se de fora; essa capacidade é ampliada e refinada pela interação”.

4 Refiro-me à expressão empregada por Habermas (1987), ao proferir o Laudatio, intitulado Hans-Georg Gadamer: urbanização da provincia heideggeriana, para referir o estilo de pensamento do filósofo, que insiste em ver as coisas em conjunto, superar as distâncias. 
A intersubjetividade é uma questão decisiva para a hermenêutica, porque ela está mais além da autoconsciência, ou seja, quer "a conservação e não a supressão da alteridade do outro no ato compreensivo" (Gadamer, 1993, p. 5).

O pensamento de Gadamer sofre influência da hermenêutica da facticidade, uma transformação da fenomenologia de Husserl, produzida por Heidegger, a qual rompe com o pensamento ordenador da metafísica e desloca o temporal do eterno. A facticidade, diz Gadamer (1999), "sublinha a factualidade do fato" e isso implica um desafio a todo o compreender. Estamos desde já no mundo sem sermos chamados e questionados. Nessa condição, a hermenêutica reconhece que se encontra "diante do incompreendido e do incompreensível" e, nessa medida, vê-se no "caminho do questionamento e é obrigada a compreender" (idem, p. 63). Mas essa constatação do incompreensível serve à hermenêutica porque renova $o$ desafio de que não se pode compreender algo totalmente outro, obscuro, e reconhece a "incompreensibilidade de não ser, que é projetado em vista de sentido" (idem, ibidem). Com a hermenêutica da facticidade, a vida "cria e erige constantemente novos encobrimentos" (idem, ibidem). Nesse duplo movimento em direção à abertura e ao encobrimento, a compreensão dependerá da arte de perguntar, de conduzir a uma autêntica conversação, em que não vigora o enquadramento em critérios predeterminados, mas o que vem à tona é o "lógos, que não é nem meu, nem seu, e que por isso sobrepuja tão amplamente a opinião subjetiva dos companheiros de diálogo que aquele que o conduz permanece sempre como aquele que não sabe" (Gadamer, 1990, p. 373).

Gadamer retoma o diálogo a partir da dialética platônica, centrado na abertura que contém a pergunta, o qual não se enquadra em pressupostos fixos que justificariam a apropriação do outro nas categorias do eu. Ao contrário, a abertura pressupõe que não se tenha uma resposta fixa, uma categoria prévia que enquadraria a resposta. A questionabilidade do que se pergunta deve permanecer em aberto, e a abertura consiste nessa capacidade de colocar em suspensão as ideias (idem, p. 369). Nessa perspectiva, há sempre algo que não pode "ser descoberto pela representação ou pela antecipação do pensamento” (Gadamer, 1999, p. 64). A possibilidade de compreensão se estrutura no diálogo, ou seja, na dialética da pergunta e da resposta que permite "um mútuo entendimento e um mundo comum"(Gadamer, 1993, p. 6).

Nessa medida, o outro suscita perguntas, e isso não se confunde com um código a decifrar, nem com qualquer intencionalidade da consciência que busca sentido; trata-se de um sentido a ser construído em entendimento. Por isso o diálogo não conduz à retenção da identidade própria de cada um, ao contrário, ele só é possível porque há um outro, uma diferença, um interlocutor radicalmente distinto com o qual dialogamos e, nesse processo, nos transformamos. Nas palavras de Gadamer (idem, p. 211): "Um diálogo aconteceu quando deixou algo dentro de nós. [...] Quando encontramos no outro algo que não havíamos encontrado em nossa experiência de mundo". O que se revela na linguagem do diálogo é a tentativa de "submergir-se em algo com alguém" (idem, p. 335). Mas, ao fazermos isso, nos expomos, porque cada um dos participantes se obriga a apresentar pressupostos, 
a rever preconceitos. Assim, o diálogo "nos põe à prova", provoca a exposição de nossas dúvidas diante daquilo que o outro contrapõe. O outro ajuda, sobretudo, a des-cobrir nossos preconceitos e a romper nossos enclausuramentos.

Entretanto, o diálogo não se restringe a expor razões de parte a parte, ele tem um "potencial de alteridade que está mais além de todo consenso" (idem, p.336). A recuperação desse potencial de alteridade no diálogo só foi possível após a denúncia de Heidegger quanto ao logocentrismo da ontologia grega. Ou seja, pode-se recolher conceitualmente a dimensão participativa do diálogo: o lógos é comum a todos, pertence a todos, o que permite construir "uma ponte para comunicar-se um com o outro e construir identidades sobre o rio da outreidade" (idem, ibidem).

A posição de Gadamer, ao retomar a dimensão aberta do diálogo, rompe com as expectativas niveladoras, que resultariam em apropriação porque a pergunta do outro o coloca como parceiro de um interminável caminho de busca, trazendo uma ética em que a integração das experiências individuais com o horizonte do outro jamais é concluída, porque a mediação interpretativa não tem limites. A experiência hermenêutica acontece justamente onde e quando algo "ganha voz". A perspectiva pedagógica do diálogo parte do pressuposto de que não somos incomunicáveis, justamente porque o lógos pertence a todos, e podemos estabelecer novos horizontes interpretativos. O horizonte encontra-se em contínua formação, na medida em que somos confrontados com a pergunta que o outro lança. Assim, compreender é sempre um processo de "fusão de horizontes" (Horizontverschmelzung). Essa bela metáfora não se refere à apropriação ou à ingênua absorção do outro, mas contém a dialética entre estranheza e familiaridade, pertença e distanciamento, constitutivas da experiência hermenêutica. A radical consciência dessa situação leva o filósofo a perceber o quanto a dificuldade do diálogo está relacionada com o estranho de nós mesmos.

Não podemos esconder de nós mesmos o quão duro e o quão imprescindível é que vivamos em diálogo. Não buscamos o diálogo apenas para compreender melhor os outros. Ao contrário, nós mesmos é que somos muito mais ameaçados pelo enrijecimento de nossos conceitos ao querermos dizer alguma coisa e ao buscarmos o acolhimento do outro [...]. O problema não está em não compreendermos o outro, mas em não nos compreendermos. Precisamente quando buscamos compreender o outro, fazemos a experiência hermenêutica pela qual precisamos romper uma resistência em nós, se quisermos ouvir o outro enquanto outro. Essa é, então, uma radical determinação fundamental de toda a existência humana e ela domina até mesmo a assim chamada autocompreensão. (Gadamer, 1999, p. 70)

Aqui o diálogo requer a determinação contra o egocentrismo, que reduz o estranho ao próprio. Contudo, essa determinação não exclui o reconhecimento da incompreensão existente em toda compreensão e também o reconhecimento da impossibilidade de a compreensão ser totalitária, ou seja, ela defronta-se com 
o pré-reflexivo e o irracional. Isso se condensa na notável afirmação de que a hermenêutica é "o saber do quanto fica, sempre, de não dito, quando se diz algo" (Gadamer, 2000, p. 211). Nessa medida, Gadamer recupera o acontecimento do outro. Entretecemos no diálogo o dito e aquilo que ainda não foi dito, porque algo sempre nos escapa, pois somos finitude. Não acolher o estranho seria o próprio fracasso do diálogo; seu êxito estaria na transformação que o estranho provoca em nós mesmos.

\section{RETOMANDO A QUESTÃO}

Pensar uma ação educativa que faça justiça à singularidade do outro requer um esforço interpretativo que remova as travas decorrentes da metafísica da subjetividade. A tradição pedagógica, fortemente ancorada em diferentes versões do idealismo e, em particular, da filosofia da consciência, tende a manter-se presa em suas categorias conceituais (sobretudo nas versões metodológicas que produzem enquadramentos tanto do aluno como do processo de aprendizagem e reduzem o diálogo a uma técnica), sem acionar o necessário movimento de abertura em que nos expomos, com o outro, a novos horizontes. Nada mais aqui se assemelha a uma posição redentora de conscientização dos alunos a respeito de uma verdade já pressuposta. Nesse empenho interpretativo a respeito da questão do outro, tanto a fenomenologia do estranho como a hermenêutica filosófica apreendem a complexidade da questão e indicam a dimensão tensional que a acompanha, mas divergem quanto à possibilidade de o diálogo abrir-se à alteridade.

A expectativa do outro só é percebida se nos desvencilhamos de nossos enclausuramentos epistemológicos e éticos. A fenomenologia do estranho de Waldenfels alerta para os danosos equívocos de uma lógica da apropriação que tentou abolir o estranho de nós próprios e reduzir o outro aos nossos esquemas interpretativos. Esse alerta é de alta relevância para a compreensão do processo pedagógico e para nossa própria autocompreensão. Mas daí não decorre a plena inacessibilidade do outro. Como alerta Schäfer (2005, p. 204), corremos o risco de mistificar o outro, atribuir-lhe um caráter "sagrado", pois não há parâmetros para saber como se comportar em relação a ele, dada a sua não apreensibilidade.

Gadamer propõe uma abordagem em que o diálogo não desfigura a alteridade, numa tentativa de apropriar-se de seu interior. Para ele, "faz parte de todo verdadeiro diálogo entender realmente o outro, fazer valer seus pontos de vista e pôr-se no seu lugar"(Gadamer, 1990, p. 389). O diálogo autêntico, aquele em que nos implicamos e do qual não sabemos o que resultará, apresenta a possibilidade de criarmos um mundo comum, decisivo para a ética em educação, pois permite o convívio, o acolhimento e a expansão de nossa própria individualidade. Uma tentativa de ultrapassar a visão monossilábica do mundo, superar o mesmo esquematismo que já nos trouxe tanta arrogância e intransigência. Só podemos ampliar nossas perspectivas éticas porque temos a capacidade de nos colocar no lugar do outro, perceber suas expectativas. $\mathrm{O}$ diálogo só se inicia porque há um outro, base para toda relação, e nisso há um éthos. 


\section{REFERÊNCIAS}

Adorno, Theodor. Ästhetische Teorie. Gesammelte Schriften. Herausgegeben von Rolf Tiedemann. Darmstadt: Wissenschaftliche Buchgeselschaft, 1998. v. 7.

Descartes, René. As paixões da alma. Tradução de Jáco Guinsburg e Bento Prado Júnior. São Paulo: Abril Cultural, 1973a.

Meditações. Tradução de Jáco Guinsburg e Bento Prado Júnior. São Paulo: Abril Cultural, 1973b.

Drummond de Andrade, Carlos. Poesia completa. Rio de Janeiro: Editora Nova Aguilar, 2001.

Gadamer, Hans-Georg. A razão na época da ciência. Tradução de Ângela Dias. Rio de Janeiro: Tempo Brasileiro, 1987.

Hermeneutik I Wahrheit und Methode: Grundzüge einer philosophischen Hermeneutik. In: Gesammelte Werke. Tübingen: Mohr Siebeck, 1990. v. 1.

. Hermeneutik II Wahrheit und Methode: Ergänzungen, Register. In:

Gesammelte Werke. Tübingen: Mohr Siebeck, 1993. v. 2.

Hermeneutik im Rublick. In:

Gesammelte Werke. Tübingen: Mohr Siebeck, 1999. v. 10.

. Retrospectiva dialógica à obra reunida e sua história de efetuação: entrevista de Jean Grodin a H.-G. Gadamer. In: Almeida, Custódio Luis da Silva de; Flickinger, Hans-Georg; Rohden, Luiz (Orgs.). Hermenêutica filosófica: nas trilhas de Hans-Georg Gadamer. Porto Alegre: EDIPUCRS, 2000.

Gehring, Petra; Fische, Matthias. Metaphysikkritik, Politikkritik, Ethik-Ausschinitte aus einen Gespräch MIT Bernhard Waldenfels, 21 dez. 1999. Journal Phänomenologie, Bochum 13, 2000. Disponível em: <http://webcache.googleusercontent.com/ search?q=cache:http://www.journal-phaenomenologie.ac.at/texte/jph13_interview. html>. Acesso em: 4 mar. 2012.

Habermas, Jürgen. Dialética e hermenêutica: para uma crítica da hermenêutica de Gadamer. Tradução de Álvaro Valls. Porto Alegre: L\&PM, 1987.

Hösle, Vittorio. Der philosophische Dialog: Eine Poetik und Hermeneutik. München: Beck, 2006.

Husserl, Edmund. Cartesianische Meditationen. In: Gesammelte Schriften. v. 8. Herausgegeben von Elisabeth Ströker. Hamburgo: Felix Meiner Verlag, 1992.

Ricoeur, Paul. Si mesmo como outro. Tradução de Agustín Neira Calvo. Madri: Siglo Veintiuno, 1996.

Schärer, Alfred. Einführung in die Erziehungsphilosophie. Weinheim e Basel: Beltz, 2005.

Todorov, Tzevetan. A conquista da América: a questão do outro. Tradução de Beatriz Perrone. São Paulo: Martins Fontes, 2003. 
Waldenfels, Bernhard. Zwischenreich des Dialogs. Sozialphilosophische Untersuchungen in Anschluß an E. Husserl. Den Haag: M. Nijhoff, 1971.

Topographie des Fremden: Studien zur Phänomenologie des Fremden I. Suhrkamp: Frankfurt am Main, 1997.

La pregunta por lo extraño. In: Seminario de Metafísica, 1998, Madrid. Anales... Madrid: Publicaciones Universidad Compultense, 1998. p. 85-98.

. The question of the other. Nova York: State University of New York Press, 2007. Zırfas, Jörg. Die Lehre der Ethik: Zur moralischen Begründung Pädagogischen Denken und Handelns. Weinheim: Deutscher Studien Verlag, 1999.

\section{SOBRE A AUTORA}

Nadja Hermann é doutora em educação pela Universidade Federal do Rio Grande do Sul (UFRGS). Professora da Pontifícia Universidade Católica do Rio Grande do Sul (PUC-RS).

E-mail: nadjamhermann@gmail.com

Recebido em abril de 2012

Aprovado em setembro de 2012 